\title{
Surgical and aesthetic rehabilitation for traumatic maxilla
}

\author{
Pelin Ozkan $^{1 *}$, P Sema Aka ${ }^{1}$, Fikret Genc ${ }^{2}$, Ahmet Keskin ${ }^{3}$ and Ayhan Gurbuz ${ }^{1}$ \\ ${ }^{1}$ Department of Prosthodontics, Faculty of Dentistry, University of Ankara, Ankara, Turkey \\ ${ }^{2}$ Department of Oral and Maxillofacial Surgeon, Vocational School of Health Services, Üsküdar University, İstanbul, Turkey \\ ${ }^{3}$ Department of Oral and Maxillofacial Surgery, Faculty of Dentistry, University of Ankara, Ankara, Turkey
}

\section{Introduction}

Severe bone and soft tissue loss need multidisciplinary treatment planning by oral and maxillofacial surgeons and prosthodontists [13]. In general, surgery is the first attempt for these conditions. In case of inadequate bone volume for dental implant placements distraction osteogenesis and augmentation are commonly preferred techniques $[4,5]$. Since each method has its own benefits and difficulties due to their standard protocols, it is better to decide to the best option for treatment on a case by case basis. Distraction osteogenesis has been considered as the most effective method for obtaining vertical bone height and soft tissue adaptation [6]. However, this method is hardly accepted by patients due to its lengthy process and discomfort. Additional issues related to this technique are; undesired outcome due to the erroneous vectoral movements of segmented bone and exposure of the device or the operation site [7-9]. In case of choosing augmentation by autogenous bone graft or allograft, it may be hard to gain vertical bone height in many cases. These conventional augmentation techniques have some additional disadvantages such as; resorption and/or infection of graft material and lack of soft tissue adaptation [10-12]. When autogenous bone graft material is chosen, morbidity of donor site has to be considered in preoperative evaluation.

On the other hand, despite the increased risk of complications, there is an agreement among many authors on benefits of using autogenous bone grafts for ridge augmentation instead of allografts due to their osteogenic properties [13-15]. It is probably more secure to protect the allografts or autogenous bone chips to prevent the particles from moving around and become encapsulated in fibrous tissue by a membrane. Using a membrane also helps to obtain a satisfactory outcome for vertical dimension of the alveolar ridge augmentation by reducing the resorption in association with graft material [13]. Use of nonresorbable membranes for large regions provides a control on the amount of graft resorption [15].

After maxillofacial structure and its integrity obtained and implants placed, prosthodontic stage starts to provide; optimum function, comfort, phonetics and natural esthetics. There are restorative and prosthetic techniques to correct the esthetic view of cases showing; soft tissue recession, missing teeth and severe bone resorption at the anterior maxilla which is regarded as the "aesthetic zone". Some authors suggest alterative, conservative prosthodontic treatments to overcome such problems at the esthetic zone. These are; pink colored composite application on root surfaces [16], partially use of pink gingival ceramics on porcelain lamiate veneers [17], fixed prosthesis with gingival colored porcelain [18], gingival shaded porcelain over titanium framework as implant superstructure [19], acrylic prosthesis with pink flanges as implant superstructure [20] or implant supported over denture prosthesis [21]. This case report describes the therapeutic phases of a trauma case involving a large regional bone defect at the maxillar alveolar process which is restored by surgical therapy and prosthetic restoration.

\section{Case description}

\section{Medical surgical phase}

A 25 year old female patient has undergone a traffic accident which caused a severe fracture of the maxillary alveolar process. Thrypsis has been noticed from midsagittal plane of maxilla to the left second premolar tooth. Teeth 11,21, 22 were absent, teeth 22, 23, 24, 25 were non-vital and showed luxation, besides the lower lip was lacerated. She had been operated in Department of Otolaryngology, University of Ankara, Faculty of Medicine. The lip was sutured and the fractures were fixed with mini plates.

\section{Dental surgical phase}

After two months, the patient was referred to the Faculty of Dentistry, University of Ankara, to receive an implant supported prosthetic restoration. However, the clinical and radiological evaluations revealed a bone resorption secondarily to infection due to the bone necrosis at the fracture site. Therefore, additional surgical operations were performed at the Department of Oral and Maxillofacial Surgery Department, University of Ankara. Miniplates were removed; infected bone tissues were curetted (Figure 1). and augmentation was performed with demineralized bone matrix (Dynagraft.D, Keystone Dental, Inc- Middlesex Turnpike Burlington MalUS ) and titanium mesh Cytoflex Titanium Mesh (Unicare Biomedical, Inc -Laguna Hills CalUS) in order to obtain adequate vertical and horizontal bone dimension for dental implant placement. Due to soft tissue insufficiency, incision site was primarily closed by turning the labial flap. Titanium membrane exposure was noticed 4 months postoperatively which may caused by repeated operations and loss of normal vascularization of the scar tissue or activity of the labium. To eliminate the infection risk of the graft material, patient was reoperated and titanium mesh was removed. Then, in order to obtain desired bone volume, harvested sypmhisis block graft was fixed with self- tapping titanium mini screws (Autodrive Screw, Osteomed, Inc-Addison Tx $\backslash$ US).

After adequate bone quality and volume was obtained, dental implants (Tapered Screw, Zimmer Dental, Inc-Aston Avenue Carlsbad, Ca, US) were placed at the site of 11, 24, 25 (Figures 2 and 3) and provisional removable partial prosthesis was inserted.

Correspondence to: Pelin Ozkan, Department of Prosthodontics, Faculty of Dentistry, University of Ankara, Ankara, Turkey, Tel: 90312 2965716, Fax: 903122123954; E-mail: pozkan@dentistry.ankara.edu.tr

Received: June 07, 2017; Accepted: July 27, 2017; Published: July 31, 2017 


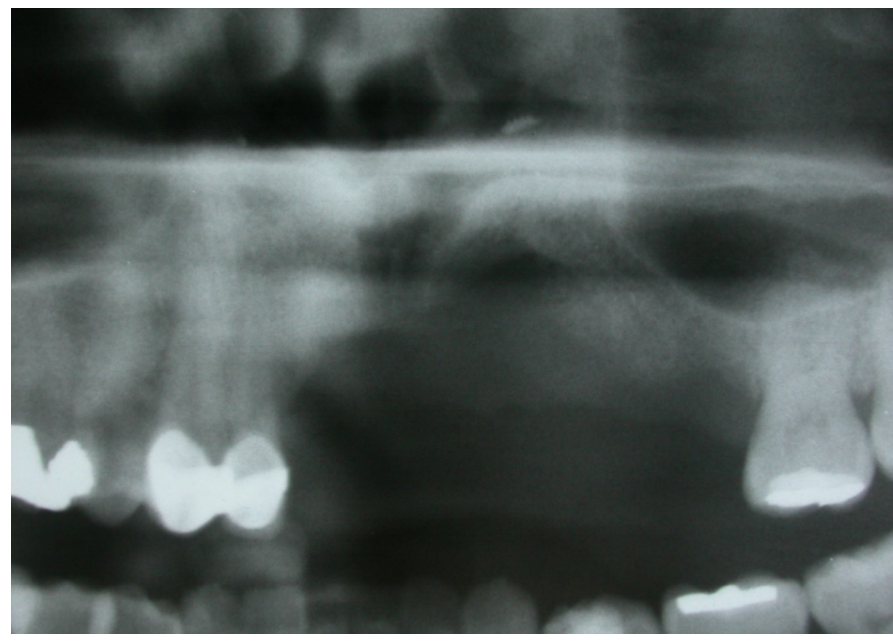

Figure 1. Before implant surgery.

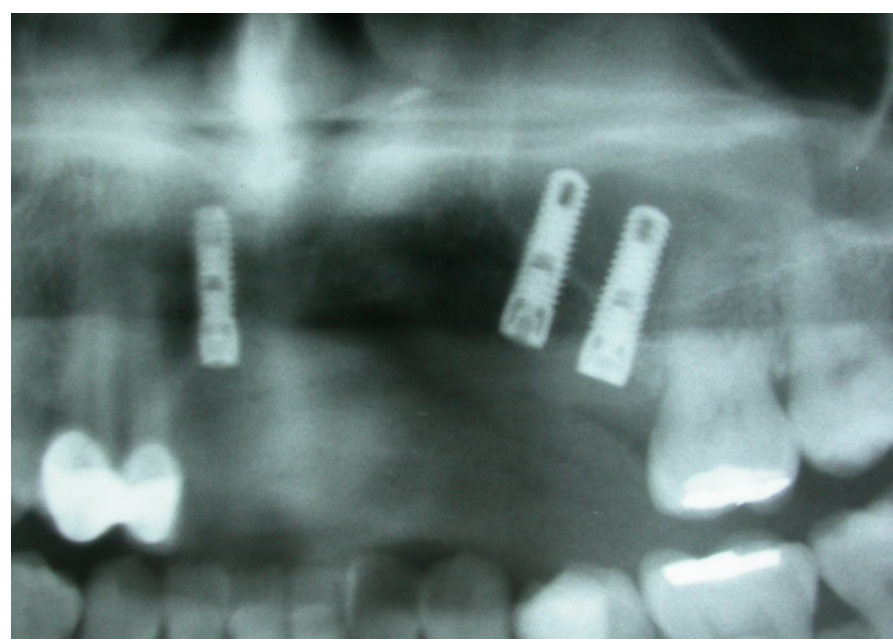

Figure 2. After implant surgery.

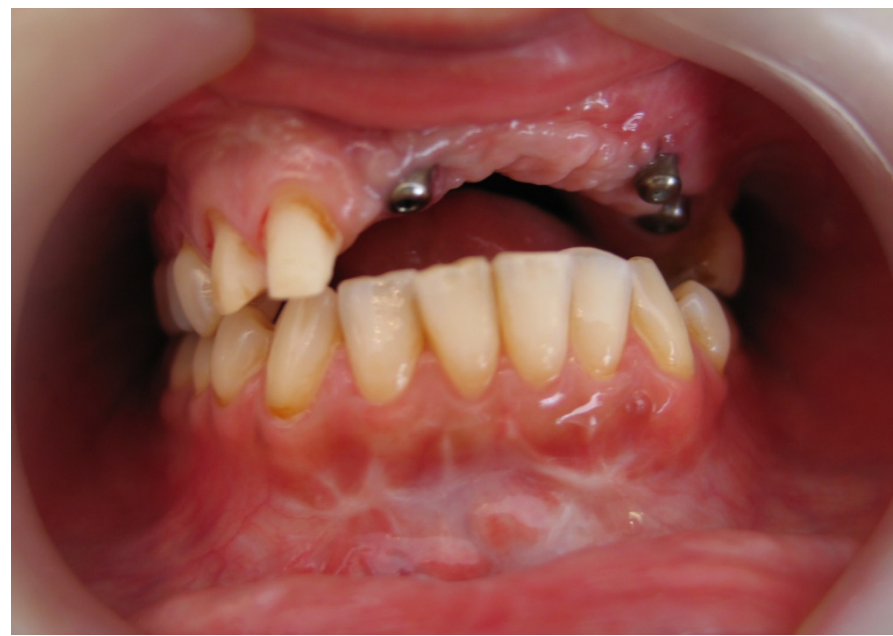

Figure 3. Implants intraoral view surgery.

\section{Dental prosthetic phase}

Following the surgical phase and insertion of implants, patient showed an asymmetric lip contour on her left side (Figure 4). Then due to luxation teeth 12 and 13 were splinted by metal ceramic crowns and a fixed partial metal ceramic over structure was constructed over the implants 11, 24, 25 where the missing soft gingival tissue were substituted by a pink gum ceramic material using IPS gingiva materials on the metal-ceramic restoration (Ivoclar Vivadent AG, Schaan/ Liechtenstein) (Figures 5-9). Oral hygiene measures were realised similar to conventional fixed partial dentures where easy flossing is possible (Figure 10). By the support provided with the fixed prosthetic restoration the lip contour was supported (Figure 11) and the smile line was naturally shaped (Figure 12).

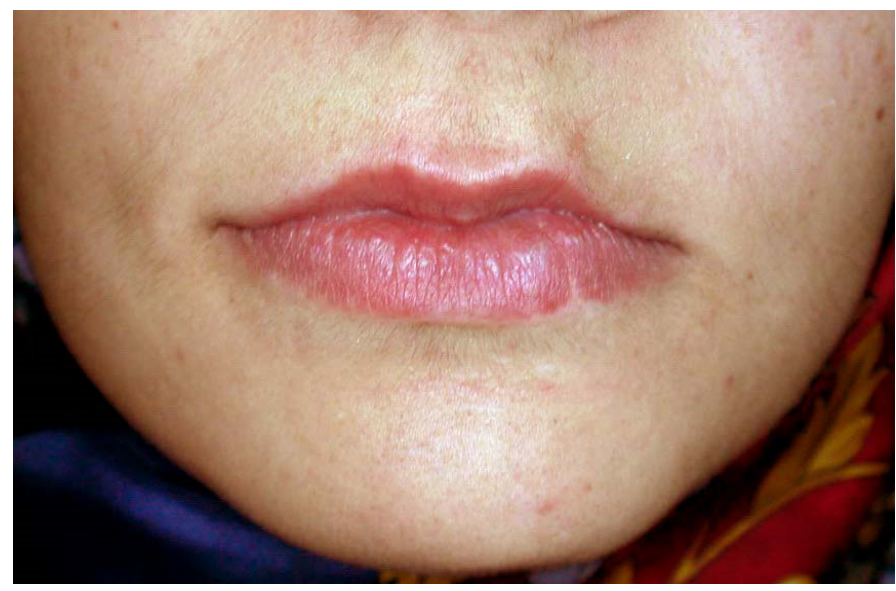

Figure 4. Asymmetric lip contour on the left side due to trauma.

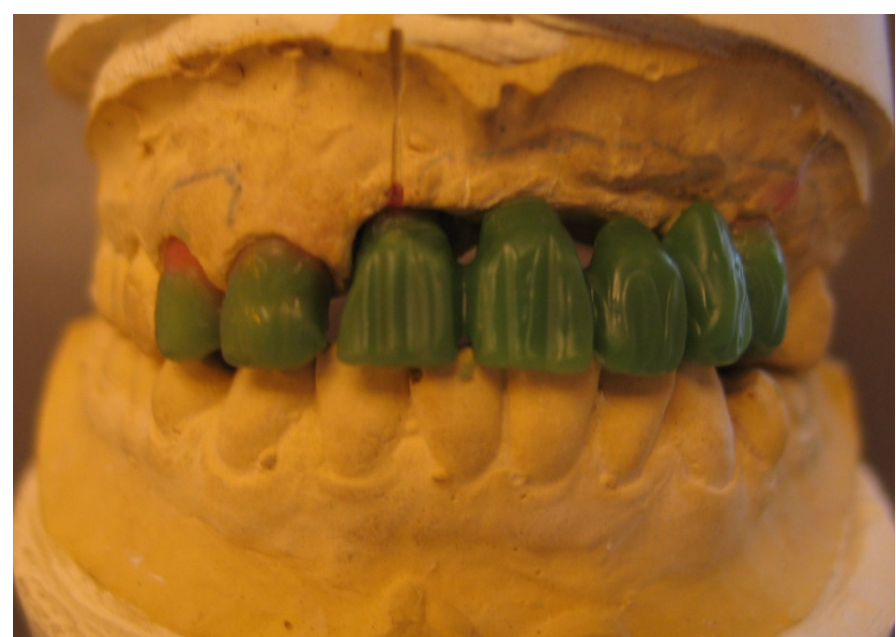

Figure 5. Laboratory wax up structure.

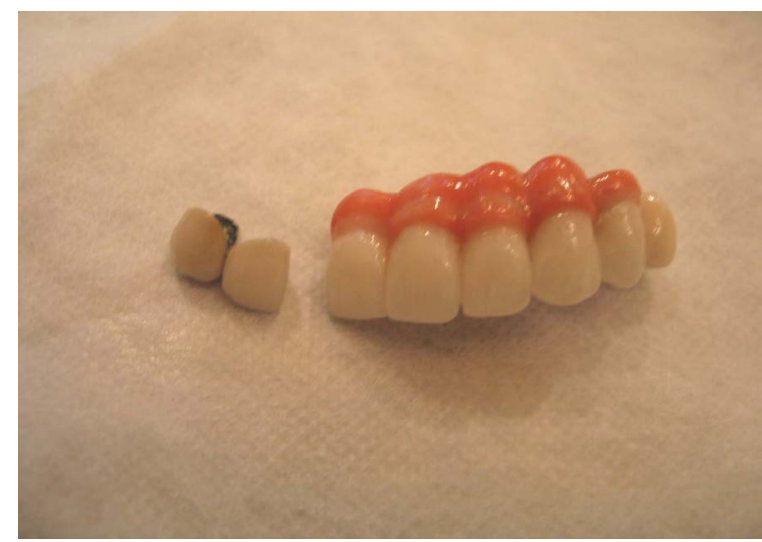

Figure 6. Ceramic overstructure with pink gum material. 


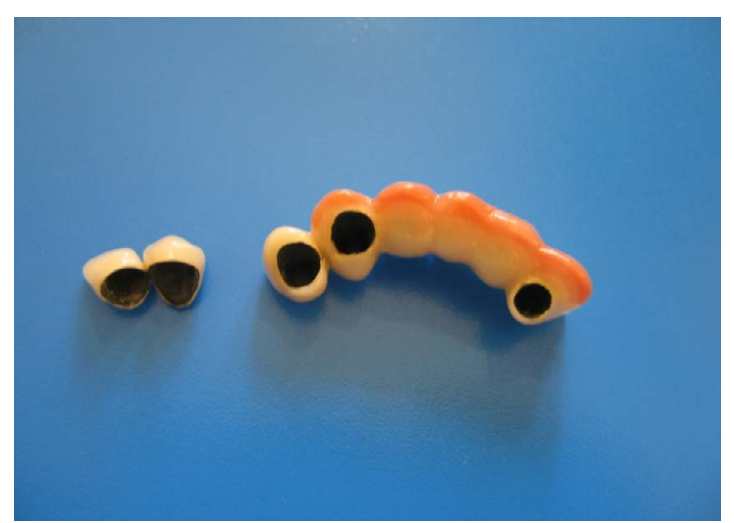

Figure 7. Palatinal border of pink ceramic gum material.

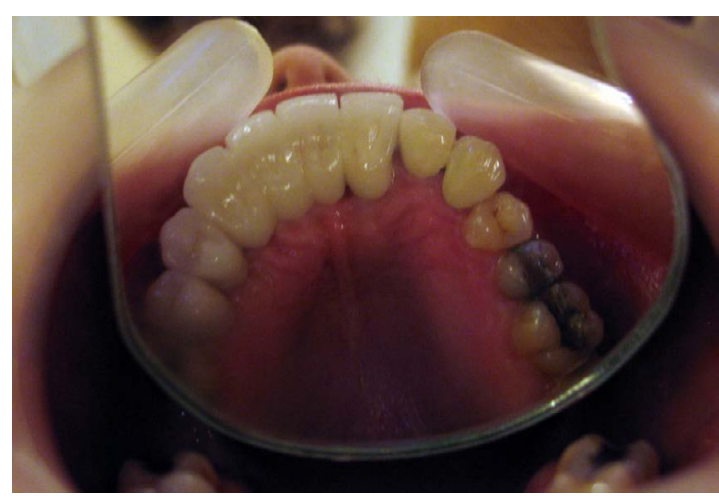

Figure 8. Palatal view of fixed partial denture

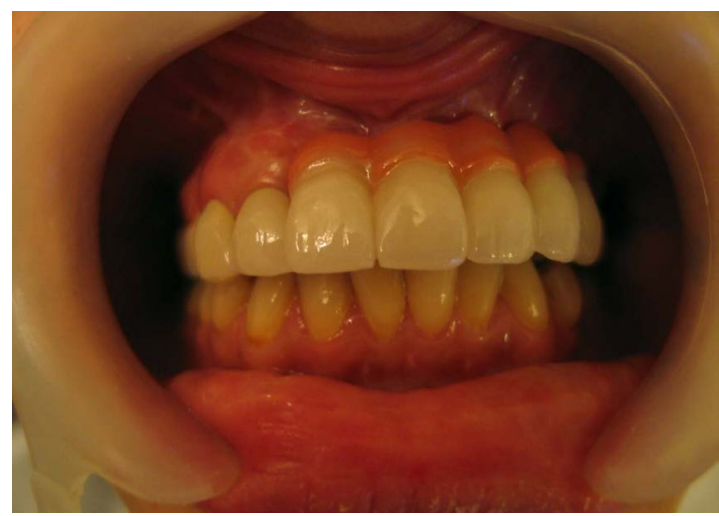

Figure 9. Posttreatment intraoral view.

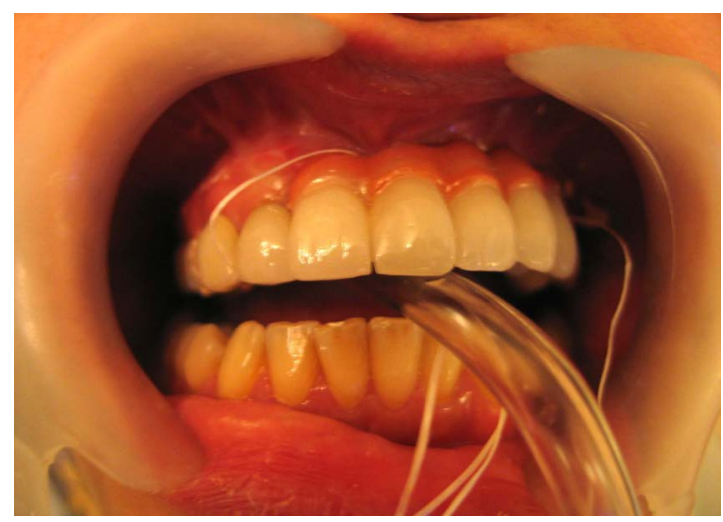

Figure 10. Hygiene can be obtaied by flossing.

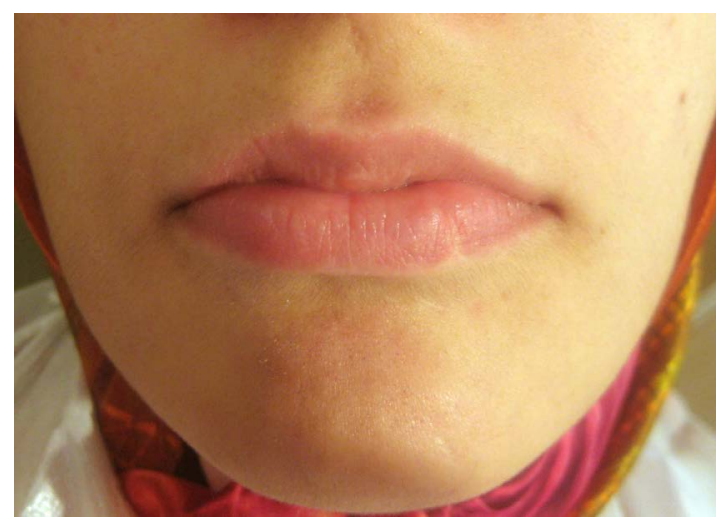

Figure 11. Supported lip contour by prosthetic treatment.

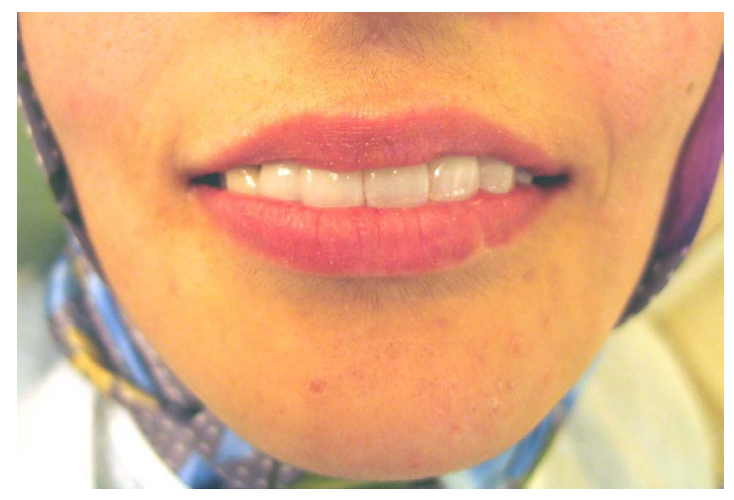

Figure 12. Posttreatment smile line.

\section{Discussion}

This clinical report explains an esthetic surgical and prosthetic approach to a trauma case which has undergone consecutive surgical operations to gain sufficient bone mass for dental implant placement. There are many surgical approaches in dental implantology for cases which show insufficient bone structure to insert dental implants at required length and diameter. Researchers proved that for such cases, clinical results were successful if graft material is supported and protected by a membrane barrier at the augmentation site [22,23]. Therefore, titanium mesh and block grafts were used in this case and oral hygiene was corrected to control the inflammation period. The most serious complication of this case was dehiscence causing the exposure of the membrane and resorbtion of the graft material during the inflammation period. For this case, improving the oral hygiene was adequate to prevent the continuation of resorbtion and sufficient bone volume was obtained with the symphisis graft with an additional operation.

In this case, adequate bone quality and volume required for dental implant placement was obtained, however the amount of bone gained after the surgery was not enough to support the left side of the patients lip which also affected the facial contour. Therefore the facial contours were corrected by the prosthetic red and white ceramic restoration. As a result esthetic, function and phonetic recovery of patient was also fulfilled. This case showed satisfying results after the surgical and implant supported prosthetic treatment.

\section{Conclusion}

In conclusion, the following results could be derived from this case:

1. Allograft augmentation and autogeous bone grafting could be 
a method of choice to obtain an acceptable bone volume before dental implant placement.

2. Satisfactory esthetic correction of the oral structures, lips and face could be provided by the support of a prosthetic reconstruction which restores the missing teeth, bone and soft tissue adequately.

\section{Acknowledgements}

Authors would like to thank to Mr. Hakan Polat for his technical labour in construction of fixed partial prosthesis.

\section{References}

1. Guven O, Gurbuz A, Baltali E, Yilmaz B, Hatipoglu M (2010) Surgical and prosthetic rehabilitation of edentulous adult cleft palate patients by dental implants. J Craniofac Surg 21: 1538-1541. [Crossref]

2. Murat S, Gurbuz A, Genc F (2011) Prosthetic rehabilitation of a patient with bilateral cleft lip and palate using osseointegrated implants and extracoronal resilient attachments: a case report. Cleft Palate Craniofac J 48: 1-6. [Crossref]

3. Gurbuz A, Murat S (2010) Implants in maxillofacial prosthesis. J Dental Scie 1: 113-122.

4. Aparicio C, Jensen OT (2001) Alveolar ridge widening by distraction osteogenesis: A case report. Pract Proced Aesthet Dent 13: 663-670. [Crossref]

5. Gaggl A, Schultes G, Kärcher H (1999) Distraction implants: a new operative technique for alveolar ridge augmentation. J Craniomaxillofac Surg 27: 214-221. [Crossref]

6. Erkut S, Uckan S (2006) Alveolar distraction osteogenesis and implant placement in a severely resorbed maxilla: A clinical report. J Prosthet Dent 95: 340-343. [Crossref]

7. Wolvius EB, Scholtemeijer M, Weijland M, Hop WC, van der Wal KG (2007) Complications and relapse in alveolar distraction osteogenesis in partially dentulous patients. Int J Oral Maxillofac Surg 36: 700-705. [Crossref]

8. Günbay T, Koyuncu BO, Akay MC, Sipahi A, Tekin U (2008) Results and complications of alveolar distraction osteogenesis to enhance vertical bone height. Oral Surg Oral Med Oral Pathol Oral Radiol Endod 105: 7-13. [Crossref]

9. Perdijk FB, Meijer GJ, Strijen PJ, Koole R (2007) Complications in alveolar distraction osteogenesis of the atrophic mandible. Int J Oral Maxillofac Surg 36: 916-921. [Crossref]

10. Van der Meij EH, Blankestijn J, Berns RM, Bun RJ, Jovanovic A, et al. (2005) The combined use of two endosteal implants and iliac crest onlay grafts in the severely atrophic mandible by a modified surgical approach. Int J Oral Maxillofac Surg 34: 152-157. [Crossref]
11. Petrungaro PS, Amar S (2005) Localized ridge augmentation with allogenic block grafts prior to implant placement: case reports and histologic evaluations. Implant Dent 14: 139-148. [Crossref]

12. Llambés F, Silvestre FJ, Caffesse R (2007) Vertical guided bone regeneration with bioabsorbable barriers. J Periodontol 78: 2036-2042. [Crossref]

13. Cordaro L, Amade DS, Cordaro M (2002) Clinical results of alveolar ridge augmentation with mandibular block bone grafts in partially edentulous patients prior to implant placement. Clin Oral Impl Res 13: 103-111. [Crossref]

14. Jakse N, Seibert FJ, Lorenzoni M, Eskici A, Pertl C (2001) A modified technique of harvesting tibial cancellous bone and its use for sinus grafting. Clin Oral Implants Res 12: 488-494. [Crossref]

15. Antoun H, Sitbon JM, Mertinez H, Missika P (2001) A prospective randomized study comparing two techniques of bone augmentation: onlay graft alone or associated with a membrane. Clin Oral Impl Res 12: 632-639. [Crossref]

16. Zalkind M, Hochman N (1997) Alternative method of conservative esthetic treatment for gingival recession. J Prosthet Dent 77: 561-563. [Crossref]

17. Capa N (2007) An alternative treatment approach to gingival recesion: gingiva-colored partial porcelain veneers: A clinical report. J Prosthet Dent 98: 82-84. [Crossref]

18. Belser U, Martin W, Jung R, Hammerle C, Schmid B, et al. (2007) ITI Treatmen Guide, Volume 1, Implant Therapy in the Esthetic Zone, Single-Tooth Replacements. Quintessence Pub. Co. Ltd. Berlin.

19. Sierraalta M, Razzoog ME (2007) Restoring a severely resorbed maxillary anterior partially edentulous space using a one-piece titanium implant fixed partial denture: A clinical report. J Prosthet Dent 97: 187-190. [Crossref]

20. Piermatti J (2007) Using CAD-CAM technology for the full-mouth, fixed, retrievable implant restoration: A clinical report. J Oral Implantol 33: 23-27. [Crossref]

21. Bilhan $H$ (2008) An alternative method to treat a case with severe maxillary atrophy by the use of angled implants instead of complicated augmentation procedures: a case report. J Oral Implantol 34: 47-51. [Crossref]

22. Kohal RJ, Mellas P, Hürzeler MB, Trejo PM, Morrison E, et al. (1998) The effects of guided bone regeneration and grafting on implants placed into immediate extraction sockets. An experimental study in dogs. J Periodontol 69: 927-937. [Crossref]

23. Hockers T, Abensur D, Valentini P, Legrand R, Hammerle CH (1999) The combined use of bioresorbable membranes and xenografts or autografts in the treatment of bone defects around implants. A study in beagle dogs. Clin Oral Implants Res 10: 487-498. [Crossref]

Copyright: (C2017 Ozkan P. This is an open-access article distributed under the terms of the Creative Commons Attribution License, which permits unrestricted use, distribution, and reproduction in any medium, provided the original author and source are credited. 